\title{
Uncanniness and the everyday: Exploring the uncanny through vernacular photography and painting
}

\author{
MUNG FEI WONG
}

\section{Abstract}

How can painting express the concept of uncanniness, as discussed by philosopher Martin Heidegger and surrealist writer Haruki Murakami? This research question is the basis of my Honours project. I am making a series of figurative paintings based on a personal collection of photographs that depict ostensibly routine everyday scenes. Using artistic techniques such as abstraction and illusion, I explore different ways of amplifying what I see as possible instances of the uncanny in these photographic sources.

As part of my Honours project I am making a series of figurative paintings that investigate the concept of uncanniness. These paintings are based on a collection of personal vernacular photographs of apparently mundane everyday scenes. I have been exploring different levels of abstraction and illusion that can illuminate possible instances of the uncanny in my photographic sources. In this essay, I will discuss the literary and artistic influences behind my project. I will evaluate the painting methods I have used thus far and propose directions for furthering these strategies in my ongoing research.

The connection between uncanniness and the banality of the everyday is the focus of my project. Martin Heidegger discusses the concept of uncanniness, 'unheimlich', in Section 40 of Being and Time and Section 30 of History of the Concept of Time. Human beings are normally absorbed in the day-to-day activities of life. We encounter and engage with things and other people in an average manner. In other words, we do things 'as one does': one drinks coffee in the morning, one uses a hammer to hit nails, one steers clear of suspicious-looking characters on the streets, and so on. However, there are instances where the familiarity of the everyday falls away, throwing us into a visceral state of anxiety. These instances are the uncanny. Importantly, Heidegger argues, there is nothing definite or predictable about the uncanny: "[anxiety] can "befall" us right in the midst of the most familiar 
environment ... [o]ne no longer feels at home'. ${ }^{1}$ However, the familiarity of the everyday quickly conceals the uncanny-in retrospect we say, 'I'm not sure what it was but something was just so weird all of a sudden'.

Surrealist writer Haruki Murakami's stories articulate how uncanniness can suddenly take hold of us amidst the familiarity of everyday life. In these stories, the protagonist's routines are momentarily disrupted by ostensibly trivial events. However, instead of being concealed by everydayness once more, increasingly absurd connections are drawn between these innocuous disturbances and other events that span various times and locations. In The Second Bakery Attack, ${ }^{2}$ a newly married couple wake up in the middle of the night, suffering from severe hunger pangs. The wife is convinced that their hunger is a curse left over from a failed bakery attack that her husband had committed with a friend in his university days. They attempt to break the curse by robbing McDonald's. In Norwegian Wood, the protagonist's visceral sense of disorientation is evocative of Heidegger's concept of 'no longer being at home': 'I raised my head and turned to see what lay beyond the phone box. Where was I now? I had no idea. No idea at all. Where was this place? All that flashed into my eyes were the countless shapes of people walking by to nowhere'. ${ }^{3}$ In his work even the most absurd, epic storylines begin with ostensibly trivial events that momentarily disrupt the protagonist's routines. I am interested in exploring how these incidences can be expressed in a painting.

These ideas about the connection between uncanniness and the everyday influenced my decision to use personal vernacular photographs as the starting point for my paintings. These photographs feature friends and family engaging in mundane activities in nondescript environments, such as walking in a park or fiddling with machines in the game arcade. In these photos I search for strange elements such as awkward expressions, ambiguous architectural space and saturated colours. I treat these elements as catalysts for disrupting the triviality of the everyday scene. My foremost studio research question is how I might employ the language and materiality of painting to bring to light these instances of uncanniness that lurk beneath the banality of the everyday photograph.

For my first explorative painting (Figure 1), I chose a photo of a friend raising a beer bottle. This photo featured blurring, tilting of architectural space and lack of tonal and chromatic distinction between objects. I used a realist approach, aiming to paint the forms and person exactly as they appear in the photograph. I intended to use a vibrant cool yellow ground to interact with the forms that are painted over it in a way that creates a sense of unease. However, I was unable to let the

1 Martin Heidegger, History of the Concept of Time, trans. Theodore Kisiel (Bloomington and Indianapolis: Indiana University Press, 1992), 289.

2 Haruki Murakami, 'The Second Bakery Attack', in The Elephant Vanishes, trans. Jay Rubin (New York: Alfred A. Knopf, 1993), 36-50.

3 Haruki Murakami, Norwegian Wood, trans. Jay Rubin (London: The Harvill Press, 2000), 350-1. 
ground show through without losing the realistic portrayal of the woman's face. Unintentionally, I had also distorted the perspective by enlarging the light switch in the background. As a result, the spatial depth of the picture plane was significantly condensed. This was reinforced by the lack of figure-ground distinction between the woman's head and the objects hanging on the door behind her, both of which were painted using pure ivory black to create a flat, matte finish.

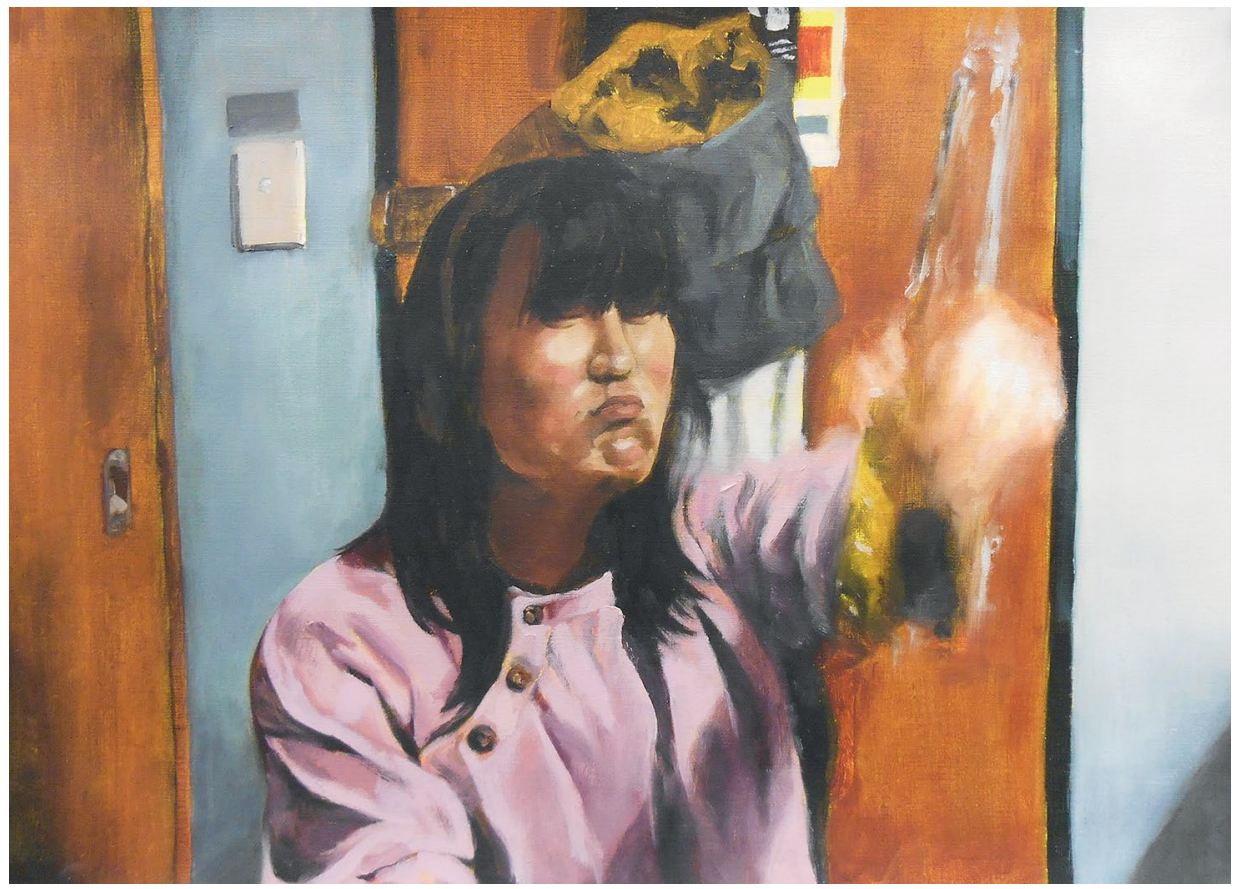

Figure 1: Mung Fei Wong, Sarah

Source: Author.

The original photograph was uniformly blurred and the forms lacked definition. Interestingly, by rendering each form using a realist approach I had clarified the image, thus heightening the contrast between the distorted hand and bottle and the other elements in the painting. This succeeds in amplifying the discomforting effect of the blurred gesture. However, it also makes the gesture the central focus of the painting and the main source of strangeness in the image. I was concerned that viewers might not understand the conceptual focus of the work, that they might think it was simply a depiction of people in strange mid-motions. More subtle ways of conveying the strange and the uncanny was required. In this painting I was able to convey the subtleties of the facial expression and the figureground distinction, but I needed to further investigate coloured grounds and the manipulation of perspective. I decided to refrain from using photographs that contained mid-motion blurs in future paintings. 
I conducted more research into different ways of manipulating figure-ground relation and perspective. These techniques are frequently used in Liu Xiaodong's paintings, which are also based on his own photos of mundane everyday life. In Fat Father and Son, Liu complicates the figure-ground relation by painting figures on top of grounds in some instances, and filling in grounds around the edge of the figure in other instances. ${ }^{4}$ For instance, the boy's left arm is clearly painted on top of the distant figure, while the shadow had been worked around the man's calves. The cropping of the boy's foot and the placement of the girl against the very edge of the picture plane are also intriguing. In Mixed Blood no. 2, the edge of the computer table recedes at a convincing angle, but the angle of the ceiling and wall seems far too steep. ${ }^{5}$ The overall composition of this painting is awkward and imbalanced, perhaps alluding to the photographic source of the painting, for example, the cameraman trying to fit everyone into the photo.

In my next study (Figure 2), I cropped a photograph to focus on the false attachment between the man's hair and the umbrella. I used a square format in which the umbrella would take up the majority of the pictorial space. Like the compositional organisation of the girl in Fat Father and Son, the pointed parts of the umbrella were to push out against the edge of the square picture plane. I cropped the man's face in order to create an awkward and cramped composition. In addition, I deliberately painted the background (sky, trees and the ambiguous plane of dark brown) as if it was a single flat plane. This was achieved by applying colours with a synthetic brush, which reduces the visibility of brush marks and texture of the oil paint, and by painting forms around rather than on top of one another. By reducing the horizontal planes into one flat surface that occupies the background and placing the umbrella and man in the foreground, the midground becomes ambiguous or even appears absent. The false attachment between the light pole and the point of the umbrella also helps to increase the illusion of a shallow space. Spatial depth is therefore condensed, amplifying the tension in the cramped compositional arrangement of the umbrella and human figures.

4 Liu Xiaodong, Fat Father and Son, 1998. Oil on canvas, 152 x 137 cm. See Jean Marc Decrop, ed. Liu Xiaodong (Hong Kong: Map Book Publishers, 2006), 108.

5 Liu Xiaodong, Mixed Blood no. 2., 1999. oil on canvas, 162.5 x 130 cm. See Decrop, ed., Liu Xiaodong, 49. 


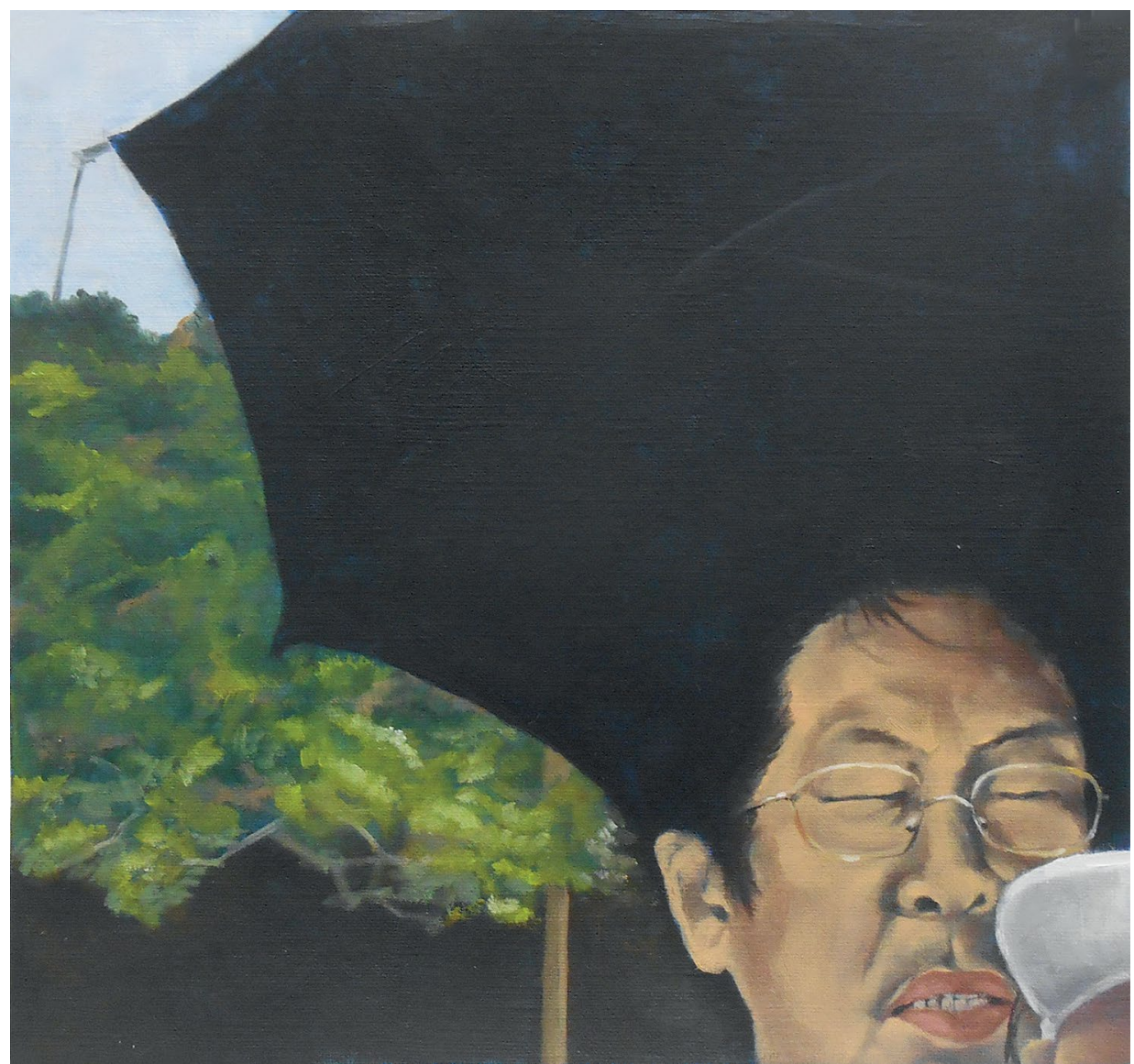

Figure 2: Mung Fei Wong, Umbrella/Man

Source: Author.

I also began to investigate whether abstracting and subtracting certain details in the photographic source from my paintings could help create a sense of the uncanny. I made several studies in which I reduced and left out information in the background in order to give more prominence to other architectural features that were providing the composition with interesting compositional axes. In Figure 3, for instance, I removed the people and tree in the background and simplified the building in the distance to put more focus on the compositional links between the white horizontal beam, the top of the figure's head, and the grey wall on the left side of the pictorial space. In this painting, I also began investigating the way in which artists such as Justin Mortimer,Jude Rae and Agnolo Bronzino use coloured grounds. In Bronzino's An Allegory of Venus and Cupid, ${ }^{6}$ for instance, a magenta

6 Agnolo Bronzino, An Allegory of Venus and Cupid, c. 1550, oil on panel, 146 x $116 \mathrm{~cm}$. See 'An Allegory of Venus and Cupid', The National Gallery, www.nationalgallery.org.uk/paintings/bronzino-an-allegory-withvenus-and-cupid, accessed 1 June 2015. 
ground is used specifically for the serpent girl's blue cape and serpent body: the edge of the red ground visibly ends just above her paw. In my study I used cool red for the majority of the picture, and warm blue to amplify the luminosity of the cadmium yellow of the Pikachu suit. The aim was to see whether the chromatic contrast between forms that had been painted on different coloured grounds could complicate the relationship between figure and ground. For instance, the blue ground pushes the yellow forward while the red ground makes the flesh tones recede, creating a cut-and-paste effect or a sense of disconnection between the figure and the clothing.

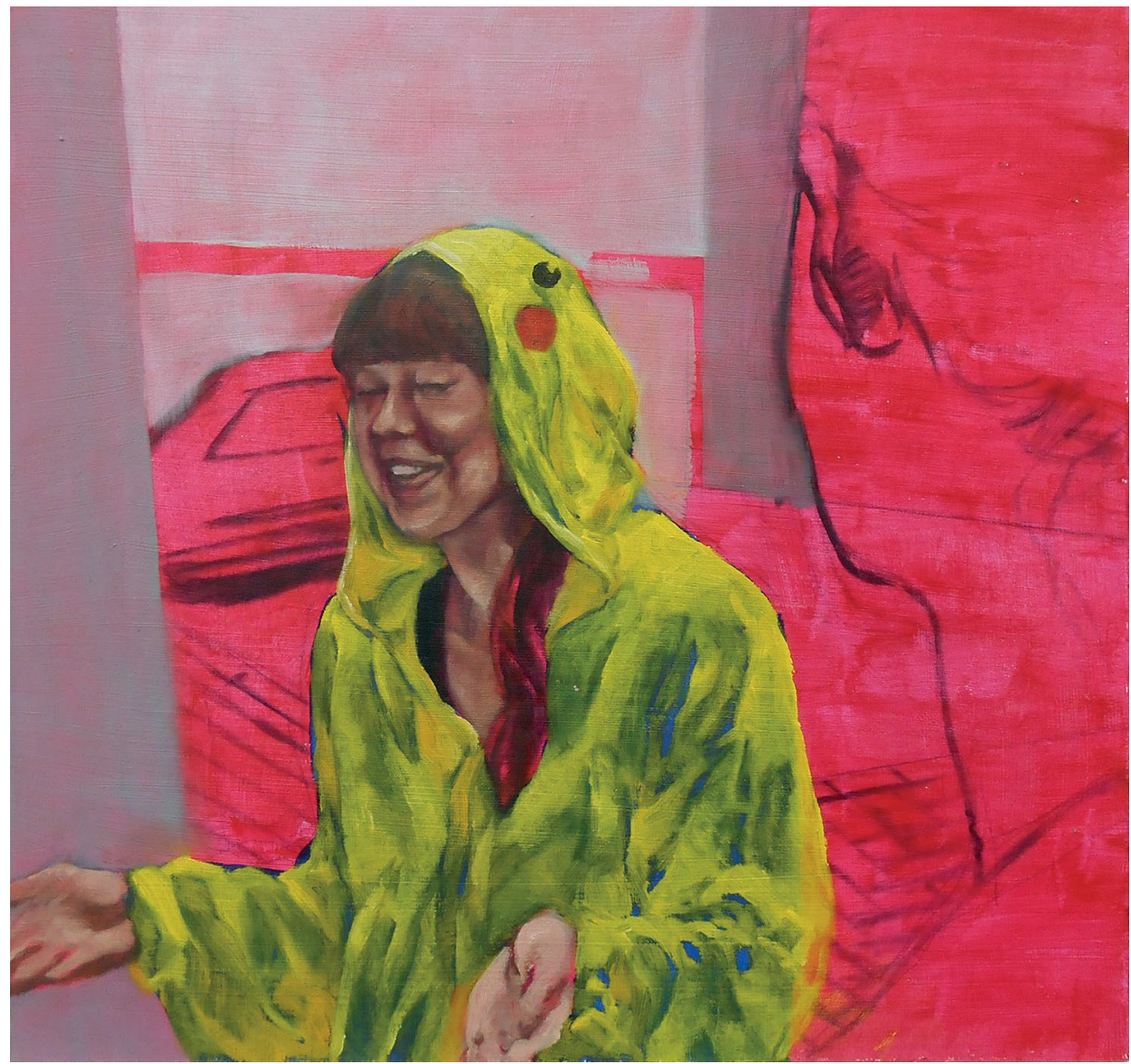

Figure 3: Mung Fei Wong, Pikachu (work in progress)

Source: Author.

At this point of my project I was having difficulties reducing detail in the image and negotiating with the coloured grounds in a way that did not diminish the realism of the painting as a whole. Thus far I had more or less been painting the photograph exactly as it appeared. I briefly ventured into experimenting with a higher level of abstraction. Borrowing German painter Norbert Bisky's technique 
of using negative space and a reduced, highly saturated colour palette, I made another version of the umbrella/man painting (Figure 4). I flattened the threedimensionality of the background by leaving some areas of the surface unpainted and representing the trees as simply flat shapes of light blue and pink. However, during peer review of this painting it was mentioned that the pastel colour palette had gendered connotations, and the reduced information suggested the graphic appearance of advertisement illustrations-ideas that are unrelated to my project. Overall, the reduced information made it too difficult for the viewers to read what was being represented in the painting and, as a result, the conceptual ideas behind it. While I made some more paintings using the same approach to see whether a series of work in the same style could help unify the paintings visually and conceptually, I was ultimately dissatisfied with this type of abstraction and illusion. They became too far removed from my photographic sources.

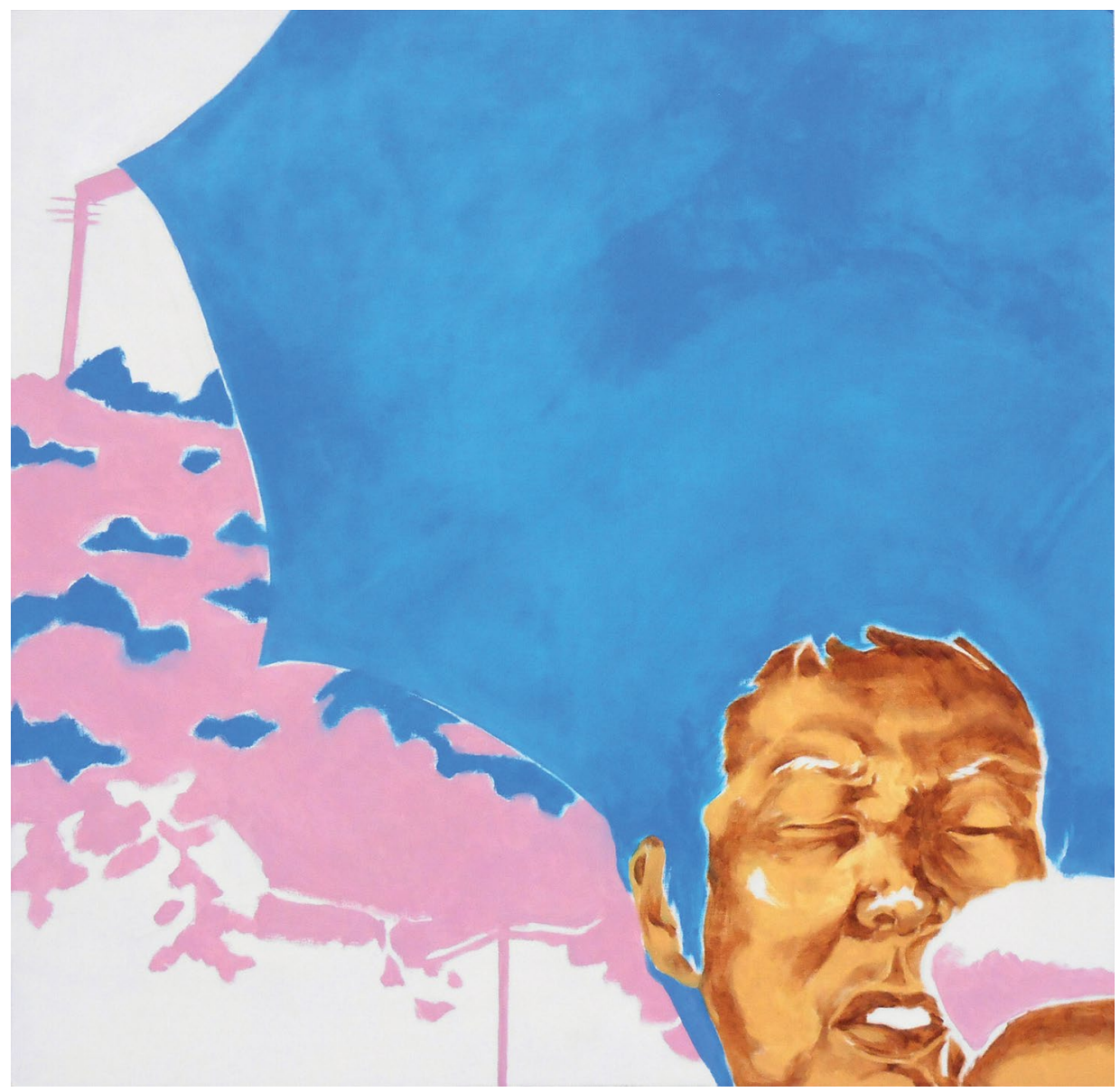

Figure 4: Mung Fei Wong, Umbrella/Man 2

Source: Author. 
For my most recent painting (Figure 5) I returned to a realistic approach. Since I had been making small A3 works so far, I decided to scale up to a $100 \times 70 \mathrm{~cm}$ board to create more room for exploring different ways of handling paint and brush marks. While examining my source photograph I discovered that poor lighting and pixelation had created speckles of red, green and yellow in the image. This gives the photo a 'buzzing' effect and also contributes to its blurriness. I attempted to reproduce this effect by dotting small blotches of cool red and cool yellow over the white gesso surface. The idea was to let this ground show through the painted forms, so that flat planes of colour and smooth gradations between mid-tones and shadow interact with the luminosity and vibration of the coloured ground. In terms of manipulating perspective, I replaced the receding space in the right area of the image with a wall. This was meant to push the figure in the bottom right corner even further into the foreground and emphasise the horizontal axes of the ceiling beams, such that the viewer will have a stronger sense of looking into a receding space. I refrained from modelling forms and figures too realistically in order to achieve the uniform, fuzzy effect of the original photo.

During my mid-year examination, examiners noted that it was still unclear what exactly it was about this photo that was uncanny; because I had painted each form with the same semi-rendered approach, no particular object stood out as the intended point of focus. It was suggested that I could render one form more than another; for example, paint the fan as realistically as possible while leaving the people semi-defined. Another suggestion was painting the same photo multiple times, but putting different objects and figures in focus in each painting. These strategies will be further explored in order to find ways to more actively direct the viewers' gaze towards particular points in my paintings.

In my research I have investigated the ways in which painting can amplify possible instances of the uncanny in everyday photographs. I have engaged with the ideas of everydayness and uncanniness in Heidegger's and Murakami's writing. Artists such as Liu and Bisky have informed the development of my painting strategies. Rather than a semi-abstracted approach, realism has proven to be a better vehicle for expressing my conceptual ideas. I have found that perspectival ambiguity, manipulation of the relationship between figure and ground, cropping, false attachment and coloured grounds can create compositional tension and an uncomfortable atmosphere. However, these techniques need refinement and enhancement in order to successfully evoke a sense of uncanniness that can elicit a visceral response from the viewers. In my future research, I will further investigate these techniques and experiment with using the same photographic source in slightly different ways in multiple paintings. 


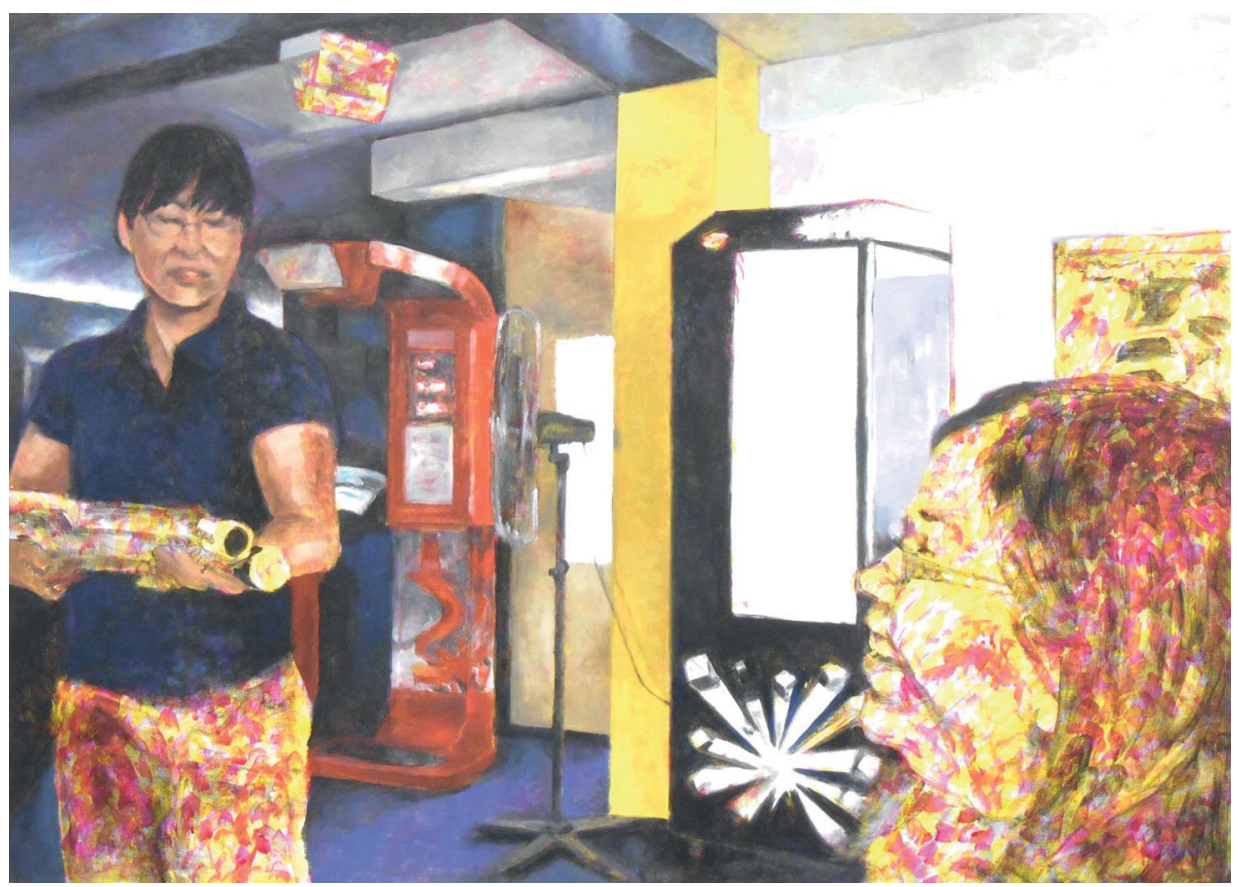

Figure 5: Mung Fei Wong, Arcade (work in progress) Source: Author.

\section{Bibliography}

Abad, José Manuel Cuesta. 'The Quotidian Gaze'. In PhotoEspaña 2009, edited by Paloma Castellanos and Luisa Lucuix. Madrid: La Fábrica Editorial, 2009.

Decrop, Jean Marc, ed. Liu Xiaodong. Hong Kong: Map Book Publishers, 2006.

Heidegger, Martin. History of the Concept of Time. Translated by Theodore Kisiel. Bloomington and Indianapolis: Indiana University Press, 1992.

Heidegger, Martin. Being and Time. Translated by John Macquarrie and Edward Robinson. New York: Harper \& Row, 1962.

McCorquodale, Charles. Bronzino. London: Chaucer Press, 2005.

Mullins, Charlotte. Painting People: The State of the Art. London: Thames and Hudson, 2006.

Murakami, Haruki. The Wind-up Bird Chronicle. Translated by Jay Rubin. London: Vintage Books, 2010. 
Murakami, Haruki. Norwegian Wood. Translated by Jay Rubin. London: The Harvill Press, 2000.

Murakami, Haruki. The Elephant Vanishes. Translated by Jay Rubin. New York: Alfred A. Knopf, 1993.

Murakami, Haruki. 'The Second Bakery Attack'. In The Elephant Vanishes. Translated by Jay Rubin. New York: Alfred A. Knopf, 1993.

Neal, Jane. Justin Mortimer. London: Haunch of Venison, 2012.

Paton, Justin. Jude Rae. Ouroborus Publishing, 2006.

Rubin, Jay. Haruki Murakami and the Music of Words. London: Harvill Press, 2003.

\section{Images cited}

All images not otherwise attributed are of the author's own work.

Agnolo Bronzino, An Allegory of Venus and Cupid, c. 1550, oil on panel, 146 x $116 \mathrm{~cm}$. From 'An Allegory of Venus and Cupid'. The National Gallery, www.nationalgallery.org.uk/paintings/bronzino-an-allegory-with-venus-andcupid, accessed 1 June 2015.

Liu Xiaodong, Fat Father and Son, 1998. Oil on canvas, 152 x $137 \mathrm{~cm}$. From: Decrop, Jean Marc, ed. Liu Xiaodong. Hong Kong: Map Book Publishers, 2006, 108.

Liu Xiaodong, Mixed blood no. 2., 1999. oil on canvas, 162.5 x $130 \mathrm{~cm}$. From Decrop, Jean Marc, ed. Liu Xiaodong. Hong Kong: Map Book Publishers, 2006, 49. 
This text is taken from The ANU Undergraduate Research Journal, Volume Seven, 2015, edited by Daniel McKay, published 2016 by ANU eView, The Australian National University, Canberra, Australia. 